\title{
Distribution of chromosome frequencies within a hybrid zone of Dichroplus pratensis (Melanoplinae, Acrididae)
}

\author{
DANIELA S. TOSTO \& CLAUDIO J. BIDAU* \\ Departamento de C.5. Biológicas, Facultad de Ciencias Exactas y Naturales, Universidad de Buenos Aires, Ciudad \\ Universitaria, Pab. $\|$ - 1428 - Capital Federat, Argentina and "Departamento de Genética, Facultad de Ciencias \\ Exactas, Quimicas y Naturales, Universidad Nacional de Misiones, Felix de Azara 174 - 3.300 - Posadas, Misiones, \\ Argentina
}

\begin{abstract}
The widespread South American melanopline grasshopper Dichroplus pratensis is chromosomally polytypic. Seven different Robertsonian translocations between six L-autosomal pairs of the standard all-telocentric karyotype were detected; several races in Argentina are characterized for being polymorphic for one to three of these rearrangements. Within contact zones monobrachial homologies between fusion metacentrics thus occur, and hybrids (complex structural heterozygotes) are formed, in whose meiosis, quadrivalents and quinquivalents prone to non-convergent orientation and unbalanced segregation are produced. We analyse the karyotypic constitution of populations of $D$. pratensis from a hybrid zone between races that, although sharing the polymorphic $3 / 4$ fusion, differ for fusions with monobrachial homologies as described above. The Sierra de la Ventana hybrid zone has certain distinctive characteristics: the frequencies and type of the fusions vary abruptly within short distances; these fusions show a mosaic pattern distribution; all the monobrachially homologous fusion metacentrics were found in high frequency. The possible origin of this hybrid zone is discussed.
\end{abstract}

Koywords: centric fusion, hybrid zone, grasshopper.

\section{Introduction}

Hybrid zones are of considerable interest to evolutionary biologists because of their frequent occurrence in nature and their involvement in a number of models of speciation (White, 1978; Hewitt, 1985, 1988, 1989; Searle, 1986, 1988; Bidau, 1988, 1991; Barton \& Hewitt, 1989; Harrison \& Rand, 1989).

Chromosomal hybrid zones between related taxa that have divergent karyotypes have been repeatedly described in different species (Hewitt, 1988). One of the most thoroughly studied examples is that of the Alpine grasshopper Podisma pedestris in which two races that differ in an $\mathrm{X}$-autosome centric fusion have a parapatric distribution with a very narrow zone of overlap in which structurally heterozygous hybrid females are produced (Hewitt, 1975, 1979; Hewitt \& Barton, 1980).

In recent years, the chromosomal speciation model that involves Robertsonian translocations with monobrachial homology has received considerable attention (Capanna, 1982; Baker \& Bickham, 1986; Searle,
1986, 1988; King, 1987; Sites \& Moritz, 1987; Bidau, 1988, 1991; Bidau et al., 1990; Redi \& Capanna, 1988; Bengtson \& Frykman, 1990). According to this model, the accumulation of independent centric fusions in different isolated populations of a species may produce metacentric chromosomes with monobrachial homology that, following hybridization, could induce postzygotic reproductive isolation due to hybrid sterility because of meiotic misbehaviour of Robertsonian multivalents (Baker \& Bickham, 1986; Redi \& Capanna, 1988; Bidau, 1991).

The analysis of hybrid zones between populations that differ in monobrachially homologous fusions provides support for this speciation model through the study of the frequency and distribution of the different karyomorphs within the zone and the meiotic misbehaviour of structural hybrids, as well as the impact of hybridity on fertility.

Different populations of the grasshopper Dichroplus pratensis are polymorphic for several fusions with monobrachial homologies and a large hybrid zone between two such chromosomal races has been dis- 


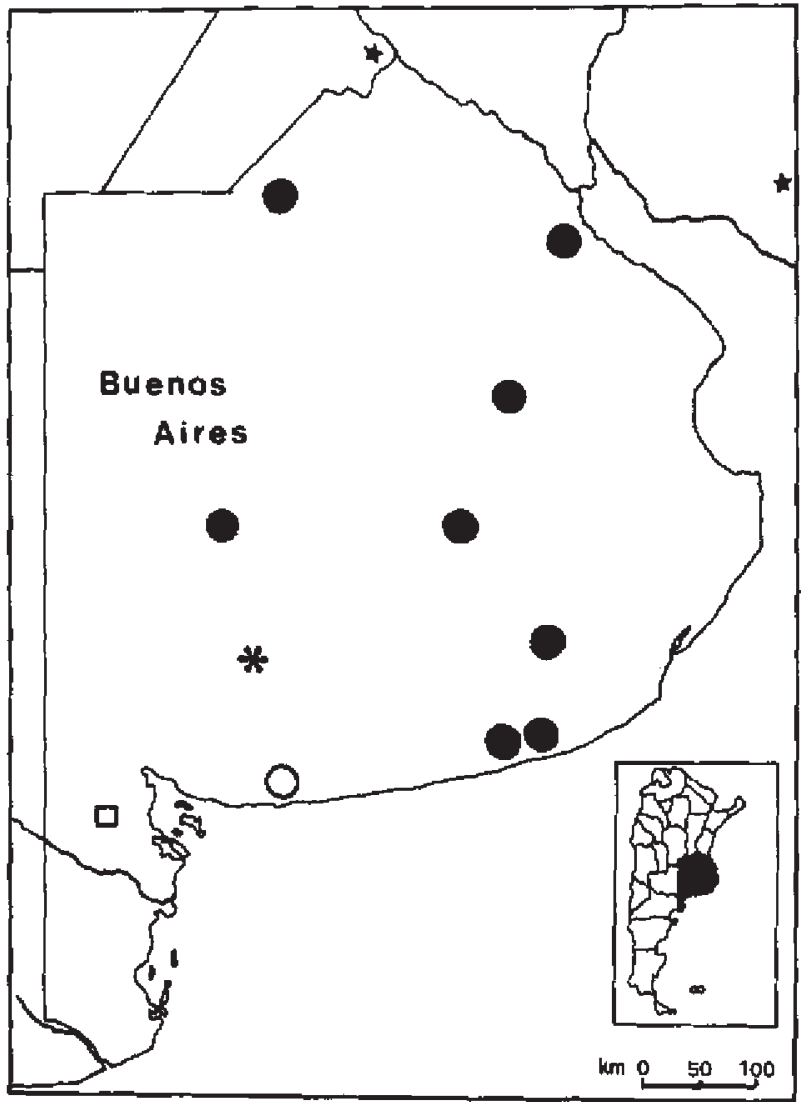

Fig. 1 Distribution of the 'Northern' (-) and the 'Southern' (O) races of $D$. pratensis in Buenos Aires Province. The asterisk marks the location of the Sierra de la Ventana hybrid zone. ( $\square$ ) Indicates the southernmost limit of the 'Northern' race. The stars correspond to the populations that belong to the 'Northern' race studied by Mesa (1971).

covered in the Sierra de la Ventana area (Buenos Aires Province, Argentina), see Fig. 1 (Bidau, 1986; Bidau et al., 1990). In previous papers (Bidau \& Mirol, 1988; Bidau, 1991) the meiotic behaviour of Robertsonian hybrids and the parental races has been described. In the present work, the distribution of chromosomal races and their hybrids within the hybrid zone are examined in order to elucidate the causes and consequences of the interaction between the chromosomally divergent populations.

\section{Materials and methods}

The present study is based on males of $D$. pratensis collected as detailed in Table 1. The identification of karyotypes was carried out in lacto-propionic orcein squashes of testes fixed in an alcohol-acetic $(3: 1)$ solution.

\section{Results}

\section{The Robertsonian system of Dichroplus pratensis}

The standard karyotype of the species, as already described by Bidau (1986) and Bidau et al. (1990), consists of 19 and 20 telocentric chromosomes in males and females, respectively, with an $\mathrm{XO} / \mathrm{XX} \&$ sex-determining system. Six autosomes are large (L1-L6), three small $(S 7-S 9)$ and the $X$ is about the size of L4.

All six L-autosomes are involved in at least seven different Robertsonian translocations in different populations of Argentina and Uruguay. An eighth fusion probably exists in a restricted area in southern Buenos Aires Province. All fusions are polymorphic (however, see below) and natural populations may contain up to three of them. The fusions found are L1/ L2, L1/L4, L1/L6, L2/L4, L2/L5, L3/L4 and L5/L6. Fusion L3/L5 probably also occurs but its existence needs corroboration.

Male meiotic behaviour regarding chiasma formation and segregation has already been studied in all possible karyomorphs (Bidau \& Mirol, 1988; Bidau, 1990, 1991).

\section{The hybrid zone at Sierra de la Ventana}

The first hybrid population sampled. The model proposed for the chromosomal evolution of $D$. pratensis, predicts the existence of hybrid zones between populations that differ in fusions with monobrachial homologies (Bidau, 1988, 1991; Bidau et al., 1990). The first indication of the existence of such zones in nature was obtained in 1983 with the record of the 7zroute population R72* (see Tables 1 and 2). The 46 males collected share a polymorphism for the L $3 / \mathrm{L} 4$ fusion while the other L-autosomes are involved in a complex fusion polymorphism due to the fact that $\mathrm{L} 1$ participates in two independent fusions: L 1/L2 and L1/L6. In addition, the L5/L6 fusion is also present in this population. Thus, four standard autosomes are inter-related through three fusions. The frequencies of the different fusions were the following: $\mathrm{L} 1 / \mathrm{L} 2: 0.25$; L.3/L4: 0.84; L5/L6: 0.27; L1/L6: 0.27; some karyotypes are shown in Fig. $2 \mathrm{a}-\mathrm{f}$.

The coexistence of fusions $\mathrm{L} 1 / \mathrm{L} 2, \mathrm{~L} 1 / \mathrm{L} 6$ and $\mathrm{L} 5 /$ L6, which have monobrachial homologies, allowed us to predict that the gametes that contain fusion chromosomes where the same element is involved in different rearrangements could produce complex structurally heterozygous zygotes. Individuals that result from these should form chains of four or five chromosomes during meiosis. According to the gametes involved. 
Table 1 Source and number of the D. pratensis males studied (all populations belong to the Buenos Aires Province)

\begin{tabular}{llll}
\hline Population & Locality & $\begin{array}{l}\text { Date of } \\
\text { collection }\end{array}$ & $\begin{array}{l}\text { Number of } \\
\text { individuals }\end{array}$ \\
\hline R72* & V. Ventana & $1 / 83$ & 46 \\
El Camping (CA) & V. Ventana & $1 / 86$ & 12 \\
El Cerro & V. Ventana & $1 / 86$ & 18 \\
El Atravesado (EA) & S. de la Ventana & $1 / 86$ & 32 \\
Zenón Peralta (ZP) & S. de la Ventana & $1 / 86$ & 17 \\
Saldungaray (S) & S. de la Ventana & $1 / 86$ & 16 \\
R72 & S. de la Ventana & $1 / 86$ & 21 \\
1 & V. Ventana & $1 / 88$ & 16 \\
2 & V. Ventana & $1 / 88$ & 11 \\
3 & V. Ventana & $1 / 88$ & 17 \\
4 & V. Ventana & $1 / 88$ & 14 \\
5 & V. Ventana & $2 / 88$ & 6 \\
6 & V. Ventana & $1 / 88$ & 13 \\
7 & V. Ventana & $1 / 88$ & 18 \\
8 & V. Ventana & $1 / 87$ & 20 \\
9 & V. Ventana & $1 / 88$ & 31 \\
10 & V. Ventana & $1 / 88$ & 11 \\
11 & V. Ventana & $2 / 87$ & 15 \\
12 & V. Ventana & $1 / 87$ & 19 \\
13 & V. Ventana & $2 / 87$ & 20 \\
14 & V. Ventana & $2 / 88$ & 4 \\
15 & V. Ventana & $2 / 88$ & 4 \\
CV4 & Co. Ventana & $1 / 88$ & 7 \\
CVm & Co. Ventana & $1 / 88$ & 9 \\
CV8 & Co. Ventana & $1 / 88$ & 8 \\
\hline & & & \\
\hline
\end{tabular}

Table 2 Karyotypic constitution of the R72* sample of Dichroplus pratensis

\begin{tabular}{ll}
\hline Karyomorphs & $n$ \\
\hline Het $3 / 4$ & 1 \\
Hom $3 / 4$ & 3 \\
Het $3 / 4 ;$ Het $1 / 6$ & 5 \\
Het $3 / 4 ;$ Hom $1 / 6$ & 4 \\
Het $3 / 4 ;$ Hom $5 / 6$ & 1 \\
Het $3 / 4 ;$ Het $1 / 2$ & 2 \\
Hom $3 / 4 ;$ Het $1 / 6$ & 5 \\
Hom $3 / 4 ;$ Het $5 / 6$ & 2 \\
Hom $3 / 4 ;$ Hom $5 / 6$ & 1 \\
Hom $3 / 4 ;$ Het $1 / 2$ & 3 \\
Hom $3 / 4 ;$ Het $1 / 2 ;$ Het $5 / 6$ & 6 \\
Hom $3 / 4 ;$ Het $1 / 2 ;$ Hom $5 / 6$ & 2 \\
Hom $3 / 4 ;$ Hom, $1 / 2$ & 1 \\
Hom $3 / 4 ;$ Hom $1 / 2 ;$ Het $5 / 6$ & 3 \\
Structural hybrids & \\
$561 ;$ Het $3 / 4$ & 1 \\
$561 ;$ Hom $3 / 4$ & 4 \\
$612 ;$ Het $3 / 4$ & 1 \\
5612 Het $3 / 4$ & 1 \\
\hline
\end{tabular}

three types of hybrids are possible: 561,612 and 5612 $(1,2,5,6$ stands for L1, L2, L5, L6). All hybrid types were found in the original population [Table 2, Fig. $2 \mathrm{~g}-\mathrm{h}$ ] (Bidau, 1990).

The frequencies of all four fusions agree well with the Hardy-Weinberg expectations (Bidau, 1984).

Analysis of chromosome frequencies within the hybrid zone. Furnished with the above described evidence, we undertook a more thorough sampling of the area of Sierra de la Ventani. A series of populations covering a large area was analysed (Fig. 3), and in all of them 2-4 of the above mentioned fusions were present, their distribution was very heterogeneous. Most populations, however, are of a hybrid nature because of the coexistence of the four fusions, while the rest are characterized by the sole existence of either L1/L2 and L5/L6, or L1/L6 (Fig. 3). As stated previously, fusion L3/L4 is present in all populations. These proportions reflect the fact that in Sierra de la Ventana two chromosomal taxa have overlapping distributional ranges: the 'Southern' race, characterized by fusions L1/L2, L3/ L4 and L5/L6, and the 'Northern' race, which is poly- 


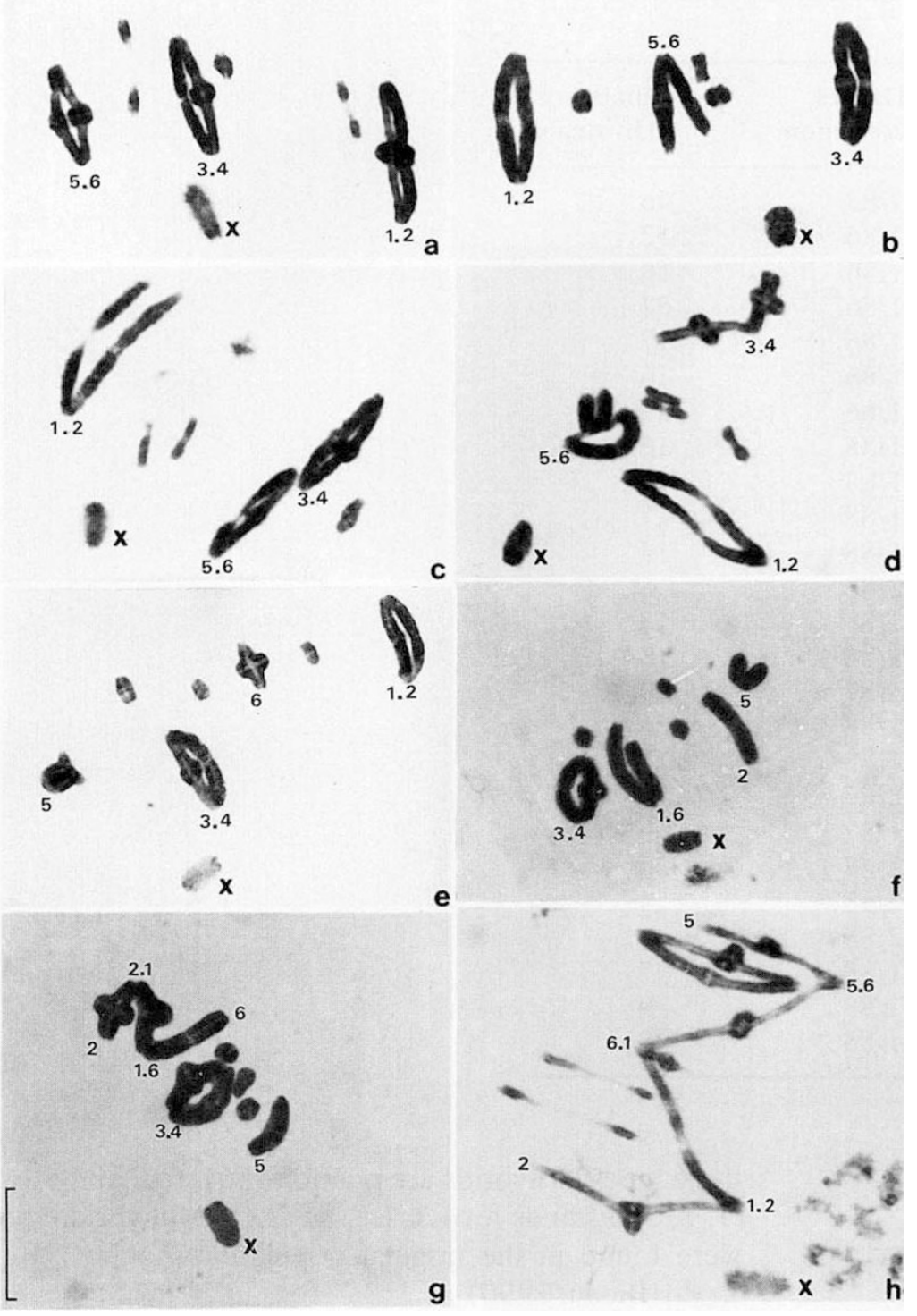

Fig. 2 Some karyomorphs of $D$. pratensis found in Sierra de la Ventana: (a) Triple L1/L2, L3/L4, L5/L6 homozygote; (b) double L1/L2, L.3/L4 homozygote, L5/L6 heterozygote; (c) double L3/L4, L5/ L6 homozygote, L1/L2 heterozygote; (d) double L1/L2, L, S/L6 homozygote, L3/L4 heterozygote; (e) double L1/L2, L3/L4 homozygote; (f) L1/L6 heterozygote, L3/L 4 homozygote; (g) and (h) two hybrid karyomorphs, both are L3/L4 homozygotes, (g) 12 type: note the L6L6/L1- L1/L2- L2 quadrivalent; (h) 5612 type: note the L5- L5/L6- L6/ L1- L1/L2-L2 quinquevalent. $\mathrm{Bar}=10 \mu \mathrm{m}$ morphic for fusion L1/L6 and L 3/L4. The latter is widely distributed in central and northern-central Argentina (from Buenos Aires and La Pampa Provinces to San Luis, Córdoba and Sante Fe Provinces) and also in Uruguay (see Fig. 1, and Bidau et al., 1990). The southernmost limit of the L1/L6 fusion seems to be the $\mathrm{Km} 784$ population (Fig. 1). The 'Southern' race seems to be restricted to the South of the Buenos Aires Province (Monte Hermoso), although the L5/L6 fusion is more widespread occupying the southern range of the species associated with fusions $\mathrm{L} 2 / \mathrm{L} 4$ and $\mathrm{L} 1 / \mathrm{L} 4$ in different localities (Bidau, 1984; Bidau et al., 1990).

Heterogeneity of chromosome frequencies in a small area within the hybrid zone. A restricted area located approximately at the centre of the zone was selected in order to analyse in a more detailed fashion the chromosomal variability described above (samples 1-15, Fig. 4).

In some populations all four fusions were present and hybrids were found; in others, the $\mathrm{L} 1 / \mathrm{L} 2, \mathrm{~L} 3 / \mathrm{L} 4$, L5/L6 system was exclusive and usually associated with higher altitudes. In only one sample was the Ll/ L6 fusion (associated with L3/L4 as usual) found at a high altitude, at the top of the Cerro de la Ventana (see Table 3 and Fig. 3). Hybrids were found in samples 6 , 7,8 and 13 (Table 3 ). In samples 7, 8 and 13 the L1/L6 fusion was only observed in hybrid individuals, although this could be due to the moderate number of individuals studied.

Chromosome frequencies vary abruptly over relatively short distances. For example, populations 6 and 7 , which are only $1000 \mathrm{~m}$ apart, show the following 
Fig. 3 Known limits of the Sierra de la Ventana hybrid zone. Only some selected populations are shown. In each case the distribution of karyotypes belonging to 'Southern' (race a) and 'Northern' (race b) races, as well as the shared and hybrids karyotypes, are indicated. The rectangle identifies the area illustrated in Fig. 4.

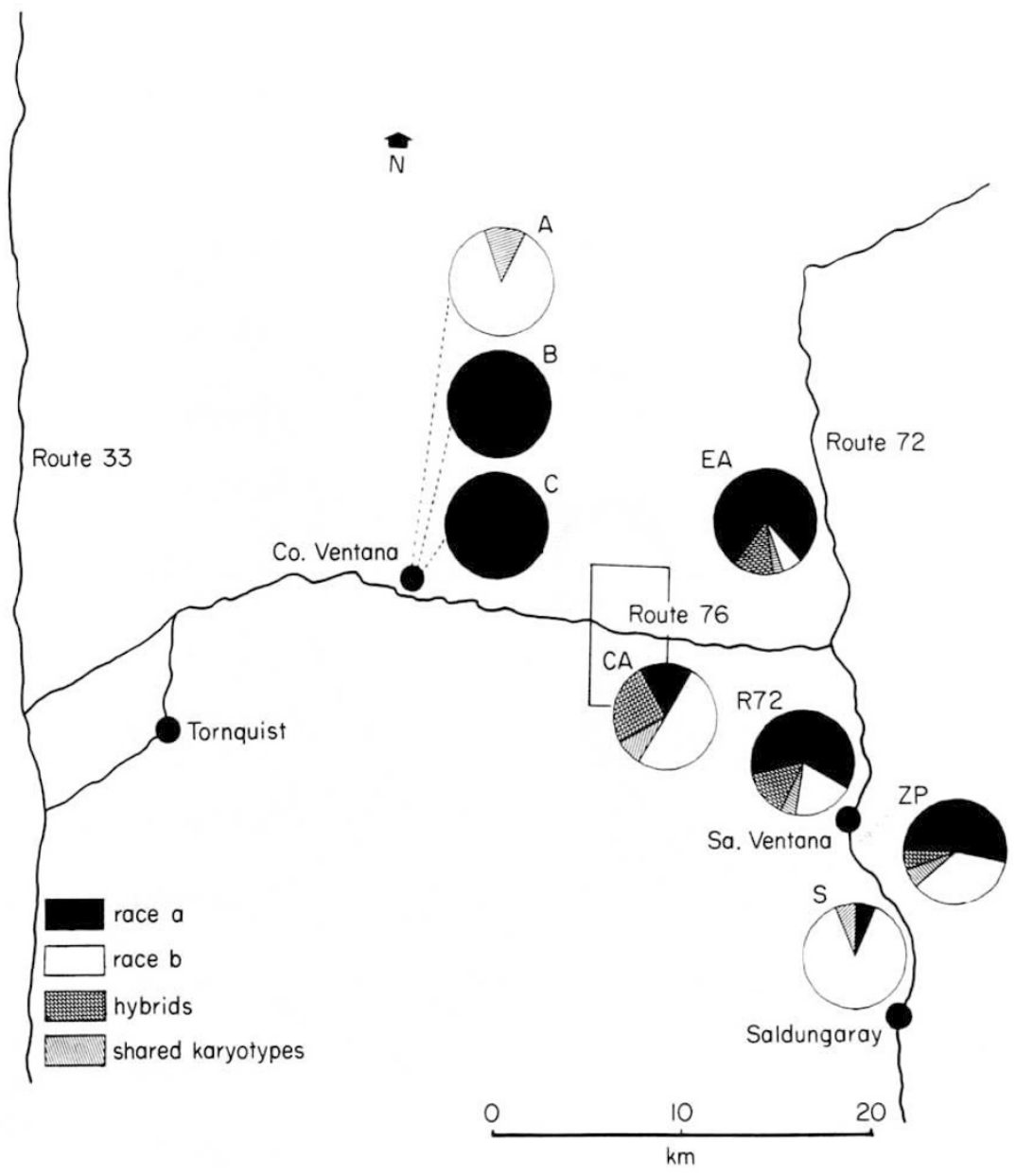

frequency distribution: sample 6, L1/L6 $(P=0.39)$, L1/L2 $(P=0.15)$, L3/L4 $(P=0.73)$, L5/L6 $(P=0.12)$; sample 7, L1/L6 $(P=0.05), \mathrm{L} 1 / \mathrm{L} 2(P=0.64), \mathrm{L} 3 / \mathrm{L} 4$ $(P=0.94)$, L5/L6 $(P=0.72)$ (Fig. 3, Table 4).

\section{Discussion}

The role of chromosomal change in speciation is controversial (White, 1978; John, 1981; King, 1987; Sites \& Moritz, 1987). Whether chromosomal polymorphisms are involved in speciation processes is also a matter of speculation (see Nachman \& Myers, 1989; Bidau, 1991) and data from natural populations are badly needed to assess their relevance to speciation processes.

In many speciation models, negative heterosis of chromosomal hybrids is central to the hypothesis of the generation of reproductive isolation (White, 1978; Sites \& Moritz, 1987). Negative heterosis is usually the result of meiotic misbehaviour in structural heterozygotes, to which the effect of linkage disequilibrium and the disruption of co-adapted supergenes after hybridization between chromosomally divergent taxa must be added (Barton \& Hewitt, 1989).

Generalizations are, however, usually flawed. We think that it is probably impossible to propose a single model of chromosomal speciation applicable to all known or suspected cases.

The Sierra de la Ventana hybrid zone has some distinctive characteristics. First, the frequencies and quality of the fusions vary abruptly over short distances $(<1000 \mathrm{~m})$ or altitudes $(<500 \mathrm{~m})$, as shown in Fig. 4 . Note also that there is an association between fusions $1 / 2-5 / 6$ and higher altitudes, while fusion $1 / 6$ is more common at lower sites. A conspicuous exception occurs, however, at Cerro Ventana, where the populations from the slope have fusions $1 / 2$ and $5 / 6$ as expected, but the population obtained from the top (about $1200 \mathrm{~m}$ above sea level) is polymorphic for fusions $1 / 6$ and $3 / 4$, the others being absent. These observations can be interpreted in several ways: (a) as the environment at Sierra de la Ventana is highly variable, ranging from rocky and sparsely vegetated hills to typical grasslands, disruptive selection could favour 


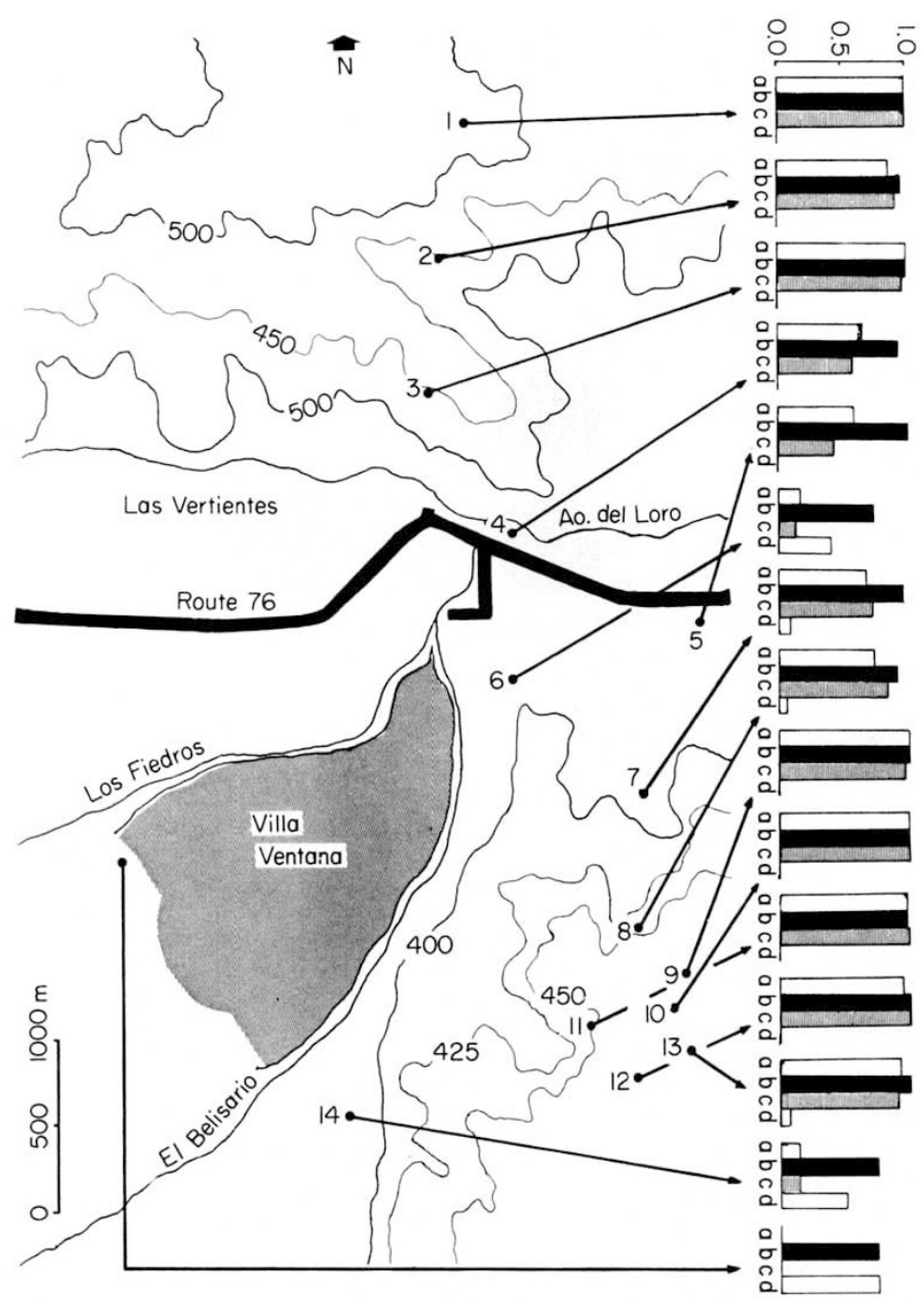

Fig. 4 Distribution and chromosome frequencies of 15 populations studied at the Villa Ventana area. References to the histograms: (a) fusion L1/L2, (b) fusion L 3/L4, (c) fusion L5/L6 and (d) fusion L1/L6. different karyomorphs in different environments; (b) the extreme patchiness of the area in which grasslands and hill slopes may be separated by very humid zones (unsuitable for D. pratensis) no more than $50-100 \mathrm{~m}$ in width, may favour random variation of chromosome forms if demes are small.

The second distinctive characteristic of the $D$. pratensis hybrid zone is that the contact between both races has possibly not been of a simple frontal type. When the distribution of chromosomal races is analysed in the area sampled, a clinal variation that follows a general northwest-southeast direction is suggested (Fig. 3). However, the chromosomal gradient does not seem to agree with the known distribution of the karyotypic races, but follows the opposite trend. That is, the Northern populations within the zone show higher frequencies of 'Southern' race karyotypes than the Southern ones. This could be due to the fact that, while the 'Northern' race is widespread and almost encircles the Sierra de la Ventana zone, the 'Southern' race is only represented in a small area in Monte Hermoso. The ecological features of the hybrid zone where different karyotypes could be adaptive to different altitudes or environments within the zone of hybridization (see above), could also distort a direct chromosomal gradient. This type of mosaic distributional pattern, presumably due to climatic factors, has been described previously (Howard, 1986, for allozymes in the crickets Allanemobius fasciatus and $A$. socius\}.

A third outstanding characteristic of the $D$. pratensis hybrid zone is the high frequency of all the monobrachially homologous fusion metacentrics. This is contrary to the result obtained by Searle $(1986,1988)$ with the common shrew, Sorex araneus. In a hybrid zone between two chromosomal races that differed in monobrachially homologous metacentrics, the frequencies of acrocentric (standard) karyotypes was high within the zone, tending to a maximum at its centre. The hypothesis put forward by this author 
Table 3 Frequencies of the four Robertsonian translocations found in the populations studied at the Sierra de la Ventana hybrid zone

\begin{tabular}{|c|c|c|c|c|}
\hline & \multicolumn{4}{|c|}{ Fusions } \\
\hline & $1 / 6$ & $3 / 4$ & $1 / 2$ & $5 / 6$ \\
\hline Population & \multicolumn{4}{|c|}{ Frequency } \\
\hline 1 & 0.00 & 1.00 & 1.00 & 1.00 \\
\hline 2 & 0.00 & 0.96 & 0.86 & 0.91 \\
\hline 3 & 0.00 & 1.00 & 1.00 & 0.97 \\
\hline 4 & 0.00 & 0.93 & 0.64 & 0.57 \\
\hline 5 & 0.00 & 1.00 & 0.58 & 0.42 \\
\hline $6^{*}$ & 0.39 & 0.73 & 0.15 & 0.12 \\
\hline $7^{*}$ & 0.06 & 0.94 & 0.64 & 0.72 \\
\hline $8^{*}$ & 0.03 & 0.90 & 0.73 & 0.83 \\
\hline 9 & 0.00 & 1.00 & 1.00 & 0.97 \\
\hline 10 & 0.00 & 1.00 & 1.00 & 1.00 \\
\hline 11 & 0.00 & 0.97 & 0.97 & 1.00 \\
\hline 12 & 0.00 & 1.00 & 0.95 & 1.00 \\
\hline $13^{*}$ & 0.05 & 1.00 & 0.93 & 0.90 \\
\hline 14 & 0.50 & 0.75 & 0.13 & 0.13 \\
\hline 15 & 0.75 & 0.75 & 0.00 & 0.00 \\
\hline CV8 (A) & 0.67 & 0.81 & 0.00 & 0.00 \\
\hline CVm (B) & 0.00 & 0.89 & 0.89 & 0.83 \\
\hline $\mathrm{CV} 4(\mathrm{C}\rangle$ & 0.00 & 0.97 & 0.91 & 0.85 \\
\hline $\mathrm{Ca}^{*}$ & 0.46 & 0.67 & 0.04 & 0.21 \\
\hline $\mathrm{EA}^{*}$ & 0.09 & 0.91 & 0.41 & 0.58 \\
\hline$Z P^{*}$ & 0.22 & 0.69 & 0.13 & 0.28 \\
\hline S & 0.66 & 0.59 & 0.00 & 0.00 \\
\hline R72* & 0.24 & 0.84 & 0.24 & 0.47 \\
\hline
\end{tabular}

*Samples where hybrids were found.

proposes that acrocentric karyotypes are favoured by selection within the zone because carriers can never produce offspring that will form complex multivalents during meiosis irrespective of the karyotype of the individuals with whom they mate.

A different pattern seems to be present in the $D$. pratensis hybrid zone. Although karyotypic fequencies do not depart significantly from Hardy-Weinberg expectation (Bidau, 1984; Tosto, 1989), the frequencies of metacentrics are almost always very high, and consequently acrocentrics are rare. It is conceivable then that, in this particular case, selection favours different adaptive gene combinations maintained by the different fusions that would be disrupted in the hybrids which, in addition, are probably subfertile. This implies actual post-mating isolation which is supported by the fact that male hybrids show a very irregular meiosis (Bidau, 1990b), and also changes in chiasma patterns of multivalents.

The origin of the $D$. pratensis hybrid zone is at present impossible to establish. Hybrid zones may result from primary or secondary contact between divergent taxa (Hewitt, 1985, 1988). Many hybrid zones of the Northern Hemisphere can be explained as a result of the last glaciation which engendered fragmentation of populations, confinement to refugia, divergence, subsequent expansion and secondary contact. However, these differences between races could also have arisen from primary (or also secondary) contact before the last ice-age (Hewitt, 1985). We think, however, that our case cannot be interpreted in these terms. The distribution range of $D$. pratensis is very broad and it is probable that the evolution of the different chromosomal systems, including those that interact at Sierra de la Ventana, occurred independently through different causes, including fragmentation of the distributional area due to climatic or geological factors in some parts of the range, colonization of marginal environments, geographical barriers, etc.

It is probable that there are several chromosomal hybrid zones within the area of distribution of the species (at least one more has been identified: Bidau, 1991). Thus, the situation at Sierra de la Ventana could have been the result of several different events. It is worth noting that this area is a transitional one that bridges the humid pampas with the Patagonian desert but as yet we have no firm evidence that habitat differences at either side of the zone are the cause of its maintenance. It is conceivable that selection against chromosomal hybrids plays an important role as well. A mixed origin for the zone is suggested by the distribution of the Robertsonian translocations with monobrachial homologies. A first contact could have occurred between a Northern and a Southern form characterized by fusions $1 / 6$ and $5 / 6$ respectively, generating a hybrid zone in which only one type of chromosomal hybrid would be formed. These fusions are common in large areas northwards and southwards of Sierra de la Ventana (see above). Fusion 1/2, however, is restricted to the hybrid zone and a small area in Southern Buenos Aires Province. This fusion could have arisen later within the zone in small populations carrying the $5 / 6$ fusion and spread subsequently (even becoming established in certain populations in association with 5/6), thus obscuring the relationships between the original chromosomal taxa.

More data on the limits of the hybrid zone as well as an exhaustive sampling in this region are needed. Further studies aimed at a better understanding of these problems are in progress.

\section{Acknowledgements}

The authors wish to express their sincere gratitude to those who helped in the collection and processing of 
grasshoppers: Tati Mirol, Dr Cristina D'Aiutolo and Claudio Jr and Pablo (CJB's sons). Special thanks are also due to Dr Esteban Hasson and Dr Pablo Colombo for reviewing the manuscript, to $\mathrm{Dr}$ Demetrio Boltovskoy for assistance with the English language, to Dr Osvaldo Reig for the literature suggested and to Ing. Jorge (Flaco) Maidana for providing computer facilities. CJB is indebted to Professor Dr Juan Hunziker in whose laboratory CJB's work on grasshopper cytogenetics started 10 years ago. Financial support from Buenos Aires University and CONICET is gratefully acknowledged.

\section{References}

BACKER, R. J. AND BICKHAN, I. W. 1986. Speciation by monobrachial centric fusions. Proc. Natl. Acad. Sci, USA, 83, $8245-8248$.

BARTON, N. H. AND HEWITT, G. M. 1989. Adaptation, speciation and hybrid zones. Namue, 341,497-503.

BENGTSON, B. O. AND FRYKMAN, I. 1990. Karyotype evolution: Evidence from the common shrew (Sorex araneus L.). $J$. Evol. Biol, 3, 85-101.

BIDAU, C. J. 1984. Estudios citogenéticos en Orthoptera de Sudamérica. Tesis de doctorado. Universidad de Buenos Aires.

BIDAU, C. J. 1986. Geographic distribution of chromosome polymorphism in Dichroplus pratensis Bniner (Melanoplinae, Acrididae) in Argentina. Proceedings of the 4th Triennial Meeting, Pan Am. Acridol, Soc, Sastcatoor, pp. $165-166$.

BIDAd, C. J, 1988. Zonas híbridas en Ortópteros: el ejemplo de Dichroplus pratensis (Acrididae). Actas I Congreso de Entomología, Argentina, pp. 109-124.

BIDAL. C. J. 1990. The complex Robertsonian system of Dichroplus pratensis (Melanoplinae, Acrididae) II. Effects of the fusion polymorphisms on chiasma frequency and distribution. Heredity, 64, 145-159.

BIDAU, C. J. 1991. Multivalents resulting from monobrachial homologies within a hybrid zone in Dichroplus pratensis (Acrididae): meiotic orientation and segregation. Heredity, 66. 219-232.

BIDAU, C. J. AND MIROL, P. 1988. Orientation and segregation of Robertsonian trivalents in Dichroplus pratensis (Acrididae). Genome, 30, 947-955.

BIDAU, C. J., TOSTO, D. S., MIROL, P. AND BELINCO, C. 1990. Geographical distribution of chromosome polymorphisms in Dichroplus pratensis (Melanoplinae, Acrididae). Genet., Select., Evol., (in press).

CAPANNA, E. 1982. Chromosomal numerical variation in animal speciation: Mus musculus, an emblematic model. In: Mechanisms of Speciation. Alan R. Liss, New York, pp. 155-177.

HARRISON, R. G. AND RAND, D. M. 1989. Mosaic hybrid zones and the nature of species boundaries. In: Otte, D. and Endler,
J. (eds), Speciation and its Consequences. Sinauer Associates, Inc., Sunderland, MA, pp, 111-133.

HEWITT, G. M. 1975. A sex-chromosome hybrid zone in the grasshopper Podisma pedestris (Orthoptera: Acrididae). Heredity, 35, 375-385.

HEWITT, G. 1979. Orthoptera. Animal Cytogenetics 3 Insecta I. Borntraeger, Berlin, pp. 98-115.

HEWITT, G. 1985. The structure and maintenance of hybrid zones. In: J. Gosalvez, C. Lopez-Fernandez and C. Garcia de la Vega (eds) Orthoptetra, Vol. 1, Fundacion, Ramón Areces, Madrid, pp. 15-54.

HEwIT, G. 1988. Hybrid zones - natutal laboratories for evolution studies. TREE, 3, 158-166.

HEwITT, G. M. 1989. The subdivision of species by hybrids zones. In: Otte, D. and Endler, J. (eds), Speciation and its Consequences, Sinauer Associates, Inc, Sunderland, MA, pp. 85-110.

HEWITT, G. M. AND BARTON, N. h. 1980. The structure and maintenance of hybrid zones as exemplified by Podisma pedestris. In: Blackman, R. L., Hewitt, $G, M$. and Ashburner, M. (eds.) Insect Cytogenetics. Blackwel] Scientific Publications Ltd, Oxford, pp. 149-169.

HOWARD, D. J. 1986. A zone of overlap and hybridization between two ground cricket species. Evolution, 40, 34-43.

JOHN, B. 1981. The role of chromosome change in the evolution of Orthopteroid insects. In: Sharma, A. K and Sharma, A. S. (eds), Chromosomes in the Evolution of Eukaryotes. Vol. 1. CRC Press, FL, pp. 1-110.

KING, M. 1987. Chromosomal rearrangements, speciation and theoretical approach. Heredity, 59, 1-6.

MESA, A. 1971. Cariología de tres especies de acrídidos del género Dichroplus (Orthoptera, Acrididae). Rev. Penana Entomol., 14, 233-237.

NACHMAN, M. W. AND MYERS, P. 1989. Exceptional chromosomal mutations in a rodent population are not strongly underdominant. Proc. Nail. Acad. Sci., USA, 86, 6666-6670.

REDI, C. A. AND CAPANNA, E. 1988. Robertsonian heterozygotes in the house mouse and the fate of their germ cells. The Cytogenetics of Mammalian Autosomal Rearrangements, Alan R. Liss, New York, pp. 315-359.

SEARLE, J. B. 1986. Factors responsible for a karyotypic polymorphism in the common shrew Sorex araneus. Proc. $R$. Soc. Lond. B, 229, 277-298.

SEARLE, J. B. 1988 . Selection and Robertsonian variation in nature: The case of the common shrew. In: The Cytogenetics of Mammalian Autosomal Rearrangements, Alan R. Liss, New York, pp. 507-531.

SITES, J. W. JR AND C. MORITZ 1987. Chromosomal evolution and speciation revisited. Syst. Zool, 36, 153-174.

TosTo, D. S. 1989. Estudios citogenéticos y morfológicos en Dichroplus pratensis (Melanoplinae, Acrididae). Tesis de Licenciatura, Universidad de Buenos Aires.

WhITE, M. J. D. 1978. Modes of Speciation. W. H. Freeman and Co., San Francisco, pp. 370-386. 